\title{
Clinical Characteristics, Treatment, and Prognosis of Diabetic Foot Disease in Macao and Beijing: A Retrospective Study
}

\author{
Yang Zhang · Nim Choi · Gangzhu Liang · Tan Li · Chun-man Ieong • \\ Sio-in Chu · Chengjie Wang • Qi Wang · Hui Li
}

Received: December 3, 2019 / Published online: April 5, 2020

(C) The Author(s) 2020

\begin{abstract}
Introduction: There has been no epidemiological study of diabetes mellitus (DM) in Macao. Also, multidisciplinary treatment is yet to be popularized and complications of DM cannot be managed promptly in this region. Therefore, this study was performed to compare the clinical characteristics, treatment, and prognosis of
\end{abstract}

Enhanced Digital Features To view digital features for this article go to https://doi.org/10.6084/m9.figshare. 11999895

Electronic supplementary material The online version of this article (https://doi.org/10.1007/s13300020-00805-1) contains supplementary material, which is available to authorized users.

Y. Zhang · T. Li · C. Wang · Q. Wang Department of Vascular Surgery, Beijing Chaoyang Hospital, Capital Medical University, Beijing 100020, China

N. Choi · G. Liang

Department of General Surgery, Hospital Conde S. Januário, Macau 999078, China

C. Ieong $\cdot$ S. Chu

Department of Radiology, Hospital Conde S. Januário, Macau 999078, China

H. Li $(\bowtie)$

Department of Thoracic Surgery, Beijing Chaoyang

Hospital, Capital Medical University, Beijing

100020, China

e-mail: huilee@vip.sina.com diabetic foot disease between patients in Macao and Beijing.

Methods: A total of 243 patients with diabetic foot disease were enrolled: 124 from a tertiary hospital in Beijing and 119 from a tertiary hospital in Macao. The clinical profiles were collected and analyzed.

Results: The surgical treatment rate in the Beijing group (96.0\%) was significantly higher than that in the Macao group (21.0\%) $(P<0.05)$. The overall mortality rate was $14.8 \%$, and cardiac failure was the most common cause (72.2\%). Monthly household income and smoking were independent factors affecting the age of onset. Age of diabetes onset was a risk factor for the occurrence of diabetic foot disease; age, duration of diabetic foot disease, and length of smoking history were independent factors affecting the severity of diabetic foot disease. Renal dysfunction and activated partial thromboplastin time were independent factors affecting the survival time of patients with diabetic foot disease.

Conclusions: Smoking may be a risk factor for the occurrence and development of diabetic foot; it can significantly reduce the onset age and aggravate the severity of this disease. The onset age of diabetic foot was lower in highincome patients, and prevention should be encouraged in this population. Elderly age may be associated with a rapidly developing and severe diabetic foot. The clinical course was also associated with the severity of diabetic foot. 
Renal and coagulation function should be closely monitored during the treatment of diabetic foot.

Keywords: Beijing; Diabetic foot; Macao; Risk factor

\section{Key Summary Points}

There has been no epidemiological study of DM in Macao. Also, multidisciplinary treatment is yet to be popularized and complications of DM cannot be managed promptly in this region.

This study was performed to compare the clinical characteristics, treatment, and prognosis of diabetic foot disease between patients in Macao and Beijing.

Smoking was a risk factor for the occurrence and development of diabetic foot; it significantly reduced the onset age and aggravated the severity of this disease.

Age of diabetic foot onset was lower in high-income patients, and prevention should be encouraged in this population.

Renal and coagulation function should be closely monitored during the treatment of diabetic foot.

\section{INTRODUCTION}

Diabetes mellitus (DM) is one of the most common metabolic diseases globally, and the prevalence of DM has been increasing in the last few decades [1]. It is expected to affect 592 million individuals by 2035, resulting in a severe and growing global health burden [2]. Diabetic foot disease is a major complication of DM that can lead to the amputation of the lower limbs and is the leading cause of death in patients with DM. Diabetic foot ulceration (DFU) is skin damage with a loss of epithelial tissue on the foot; it can involve the corium, muscles, and even bone. DFU has high morbidity and mortality [3]. Histopathologically, DFU is characterized by ischemia, neuropathy, and infection [4]. Additionally, approximately $35 \%$ of all patients with DFU have concomitant peripheral arterial disease (PAD) [5]. PAD is usually clinically underdiagnosed, as less than $25 \%$ of all PAD cases experience notable symptoms such as intermittent claudication and rest pain [6]; nevertheless, it has been identified as an independent risk factor for DFU and amputation [7]. PAD reduces the blood supply to the lower extremities, which may aggravate the foot infection, delay wound healing, and even lead to gangrene. Therefore, early diagnosis and management of DFU and PAD are crucial in order to improve the clinical prognosis of diabetic foot disease [3].

$\mathrm{DM}$ is the fifth leading cause of death in Macao. The incidence of DM in the general population of Macao is $8.6 \%$, and an increasing number of young adults are affected. DM severely impairs the social labor force and the average life expectancy in this region. There is no epidemiological study of DM in Macao. Also, multidisciplinary treatment is still uncommon and complications of $\mathrm{DM}$ are not managed promptly. Therefore, in the current study, we compared the clinical characteristics, treatment, and prognosis of diabetic foot disease between patients in Macao and Beijing.

\section{METHODS}

\section{Subjects}

This study enrolled a total of 243 patients with diabetic foot disease between January 2013 and December 2018, including 124 patients from a tertiary hospital in Beijing (the Beijing group) and 119 patients from a tertiary hospital in Macao (the Macao group). This study was approved by the local ethics committee. Written informed consent was obtained from each participant. This study was performed in accordance with the Helsinki Declaration of 1964 and its later amendments.

Patients who were diagnosed with diabetic foot through medical history collection, clinical 
examination, imaging examination, and laboratory examination were included. Patients who missed multiple clinical examinations and those for whom there were substantial missing data were excluded. Patients with severe mental illness or a disturbed consciousness who could not complete the investigations as required were excluded.

Among the 243 patients, 232 were Han (95.5\%) and 11 were other ethnicities (4.5\%). In the Beijing group, 120 patients were Han $(96.8 \%)$ and $4(3.2 \%)$ were other ethnicities. In the Macao group, 112 patients were Han (94.1\%) and 7 (5.9\%) were other ethnicities. There was no significant difference in the distribution of ethnic groups between the two groups according to the results of a chi-square test $\left(\chi^{2}=0.992, P=0.319\right)$.

\section{Diagnosis}

Diagnosing diabetic foot early is difficult. Patients usually consult a doctor when they develop clinical symptoms such as foot infection, decreased or lost sensation, foot deformities, and intermittent claudication of the lower limbs. Foot ulcer is the most common clinical manifestation of diabetic foot, with neuropathy, vascular disease, and infection as the main causes.

The current view is that ulcers can cause infection rather than being caused by infection. Therefore, we consider DM patients with infected wounds of the foot that have not healed after 14 days to have diabetic foot disease, and these patients require further relevant examination.

The ankle-brachial index (ABI) test is the main test for diabetic vascular disease. Neuropathy is usually diagnosed based on clinical manifestations and the diagnosis is corroborated by neuroelectrophysiology. A $10 \mathrm{~g}$ nylon wire is applied to four different parts of the foot to check for loss of sensation, and diabetic foot is diagnosed based on positive results from any of the following tests: the $128 \mathrm{~Hz}$ tuning fork test; vibration acupuncture; the ankle reflex test; and the vibration perception threshold.

\section{Data Collection}

The clinical profiles and follow-up data were collected and analyzed. General characteristics included age, sex, marital status, occupation, and income. Clinical variables included smoking history, hypertension, hyperlipidemia, coronary heart disease, stroke, renal dysfunction, peripheral neuropathy, retinopathy, history of stent implantation, and the progression time of diabetic foot disease (i.e., the time from the diagnosis of DM to the diagnosis of diabetic foot disease). Laboratory parameters included serum alanine transaminase level (ALT), serum aspartate aminotransferase level (AST), serum triglyceride level (TG), serum total cholesterol level (TC), serum low-density lipoprotein cholesterol level (LDL-C), serum high-density lipoprotein cholesterol level (HDL-C), red blood cell count (RBC), platelet count (PLT), creatinine level (Cr), blood urea nitrogen level (BUN), hemoglobin level (HGB), activated partial thromboplastin time (APTT), blood glucose level, and urine protein. Cardiac function parameters included left ventricular interior diameter (LVID), left ventricular end-diastolic diameter (LVEDD), and left ventricular function (LVEF).

\section{Statistical Analysis}

SPSS 24.0 software (IBM Corp., Armonk, NY, USA) was used for statistical analyses. All analyses were two-sided, and the statistical significance level was set at 0.05 . Continuous variables were expressed as the mean \pm standard deviation (SD) when normally distributed or the median (interquartile range, IQR) when nonnormally distributed. Categorical variables were presented as frequencies (percentage, \%). Univariate statistical analysis utilized the independent-sample $t$ test, analysis of variance (ANOVA), chi-square test, or rank-sum test, as appropriate. To identify the potential risk factors for $\mathrm{DM}$, multivariate logistic regression analyses, multiple linear regression analyses, and Kaplan-Meier survival analyses were used. 
Table 1 Characteristics of patients with DM

\begin{tabular}{|c|c|c|c|c|}
\hline Variable & Beijing group $(n=124)$ & Macao group $(n=119)$ & $\chi^{2} / Z$ value & $P$ value \\
\hline \multicolumn{5}{|l|}{ Sex } \\
\hline Male & $85(68.5 \%)$ & $65(54.6 \%)$ & 4.985 & 0.026 \\
\hline Female & $39(31.5 \%)$ & $54(45.4 \%)$ & & \\
\hline \multicolumn{5}{|l|}{ Marital status } \\
\hline Single/divorced/widowed & $54(43.5 \%)$ & $17(14.3 \%)$ & 25.143 & $<0.001$ \\
\hline Married/cohabiting & $70(56.5 \%)$ & $102(85.7 \%)$ & & \\
\hline \multicolumn{5}{|l|}{ Smoking history } \\
\hline Never smoking & $66(53.2 \%)$ & $71(59.6 \%)$ & 3.983 & 0.136 \\
\hline Already quit smoking & $7(5.6 \%)$ & $12(10.1 \%)$ & & \\
\hline Current smoking & $51(41.2 \%)$ & $36(30.3 \%)$ & & \\
\hline \multicolumn{5}{|l|}{ Number of cigarettes smoked } \\
\hline 0 cigarettes & $66(56.4 \%)$ & $71(66.4 \%)$ & -1.341 & 0.180 \\
\hline $1-20$ cigarettes & $33(28.2 \%)$ & $21(19.6 \%)$ & & \\
\hline$\geq 21$ cigarettes & $18(15.4 \%)$ & $15(14.0 \%)$ & & \\
\hline \multicolumn{5}{|l|}{ Length of smoking history } \\
\hline 0 year & $66(56.4 \%)$ & $71(66.4 \%)$ & -2.582 & 0.010 \\
\hline $1-30$ years & $11(9.4 \%)$ & $26(24.3 \%)$ & & \\
\hline$\geq 31$ years & $40(34.2 \%)$ & $10(9.3 \%)$ & & \\
\hline
\end{tabular}

\section{RESULTS}

In the Beijing group, there were 85 males and 39 females with an average age of $70.86 \pm 9.60$ years; 54 patients lived alone and 70 patients lived together with his/her spouse. In the Macao group, there were 65 males and 54 females with an average age of $67.08 \pm 13.192$ years; 17 patients lived alone and 102 patients lived together with his/her spouse. The age and the male-to-female ratio in the Beijing group were higher than those in the Macao group $(P<0.05)$. There was no significant difference in smoking history $(P=0.136)$ or the number of cigarettes smoked $(P=0.180)$ between the two groups. The length of smoking history in the Beijing group was significantly longer than that in the Macao group
$(P=0.010)$. The incidence rates of tumors, hypertension, hyperlipidemia, renal dysfunction, peripheral neuropathy, and retinopathy were significantly higher in the Beijing group than in the Macao group $(P<0.01)$. These results are summarized in detail in Tables 1 and 2.

TG, TC, LDL-C, Cr, LVID, LVEDD, and the incidence of segmental wall motion abnormalities were significantly higher in the Macao group than in the Beijing group $(P<0.05)$. However, fasting blood glucose, postprandial blood glucose, and LVEF were significantly lower in the Macao group than in the Beijing group $(P<0.05)$. These results are provided in detail in Table 3.

The age of diabetic foot disease onset was significantly lower in the Macao group than in 
Table 2 Concomitant diseases in patients with DM

\begin{tabular}{lclllr}
\hline Concomitant disease & Total $(\boldsymbol{n}=\mathbf{2 4 3})$ & Beijing group $(\boldsymbol{n}=\mathbf{1 2 4})$ & Macao group $(\boldsymbol{n}=\mathbf{1 1 9})$ & $\boldsymbol{\chi}^{\mathbf{2}}$ value & $\boldsymbol{P}$ value \\
\hline Tumor & $24(9.9 \%)$ & $3(2.4 \%)$ & $21(17.6 \%)$ & 15.819 & $<0.001$ \\
Hypertension & $179(73.7 \%)$ & $82(66.1 \%)$ & $97(81.5 \%)$ & 7.407 & 0.006 \\
Hyperlipidemia & $102(42.0 \%)$ & $16(12.9 \%)$ & $86(72.3 \%)$ & 87.867 & $<0.001$ \\
Coronary heart disease & $67(27.6 \%)$ & $27(21.8 \%)$ & $40(33.6 \%)$ & 3.713 & 0.054 \\
Stroke & $52(21.4 \%)$ & $22(17.7 \%)$ & $30(25.2 \%)$ & 2.014 & 0.156 \\
Renal dysfunction & $65(26.7 \%)$ & $7(5.6 \%)$ & $58(48.7 \%)$ & 57.555 & $<0.001$ \\
Peripheral neuropathy & $37(20.8 \%)$ & $2(3.4 \%)$ & $34(29.4 \%)$ & 16.221 & $<0.001$ \\
Retinopathy & $57(34.3 \%)$ & $6(9.8 \%)$ & $51(48.6 \%)$ & 25.677 & $<0.001$ \\
\hline
\end{tabular}

the Beijing group $(P=0.026)$. The durations of $\mathrm{DM}$ and diabetic foot disease as well as the time taken to progress to diabetic foot disease were significantly shorter in the Macao group than in the Beijing group, and the ankle-brachial index was higher in the Macao group (all $P<0.05$ ). These results are summarized in detail in Table 4.

In the Beijing group, the surgical treatment rate was $96.0 \%$, which was significantly higher than that in the Macao group (21.0\%) $(P<0.001)$ (Table 5$)$. A total of 36 patients died, and cardiac failure was the most common cause $(72.2 \%)$. There was no significant difference in the mortality rate $(P=0.114)$ or cause of death $(P=0.883)$ between the Beijing group and the Macao group (Table 6).

Multivariate linear regression analysis showed that total monthly household income and smoking history were independent risk factors associated with the onset age of diabetic foot disease (Tables 7, 8). Additionally, the onset age of DM and the length of smoking history were independent risk factors associated with the progression time of diabetic foot disease (Tables 9, 10). Moreover, the severity of diabetic foot disease was categorized into four groups according to the degree of vascular stenosis: mild (25-49\%), moderate (50-74\%), severe (75-99\%), and occlusion (100\%) (Table 11). Multivariate linear regression analysis revealed that age, the clinical course of diabetic foot disease, and length of smoking history were independent risk factors associated with the severity of diabetic foot disease (Tables 12, 13). Kaplan-Meier analysis showed that the survival time was significantly longer in the Beijing group than in the Macao group $(P=0.002)$ (Fig. 1). Cox regression analysis showed that renal dysfunction and APTT were independent risk factors associated with the survival time of patients with diabetic foot disease (Tables 14, 15).

\section{DISCUSSION}

The patients in the Beijing group were older than those in the Macao group, and the patients in the Macao group had more comorbidities during the early stage of DM. These findings indicate that the prevention and treatment services in Beijing are better than those in Macao. Further analyses revealed that hyperlipidemia, renal dysfunction, and cardiac dysfunction are more common in Macao than in Beijing, which may be related to differences in dietary patterns and lifestyles as well as inadequate education in Macao. During previous work, we found that residents in Macao have a lack of knowledge regarding the prevention and treatment of DM, and that irregular blood glucose monitoring and untimely treatment severely impair public health in Macao. In patients with DM, poor capillary perfusion affects wound healing and the formation of collateral circulation. Additionally, arterial occlusion aggravates the perfusion deficiency in 
Table 3 Laboratory results in patients with DM

\begin{tabular}{|c|c|c|c|c|c|}
\hline Variable & Total $(n=243)$ & $\begin{array}{l}\text { Beijing group } \\
(n=124)\end{array}$ & $\begin{array}{l}\text { Macao group } \\
(n=119)\end{array}$ & $\begin{array}{l}\text { Statistical } \\
\text { value }\end{array}$ & $P$ value \\
\hline \multicolumn{6}{|l|}{ Serum lipid levels } \\
\hline $\mathrm{TG}(\mathrm{mmol} / \mathrm{L})^{\mathrm{a}}$ & $2.28 \pm 1.482$ & $1.82 \pm 1.151$ & $2.77 \pm 1.631$ & -5.230 & $<0.001$ \\
\hline $\mathrm{TC}(\mathrm{mmol} / \mathrm{L})^{\mathrm{a}}$ & $5.07 \pm 1.713$ & $4.53 \pm 1.187$ & $5.62 \pm 1.985$ & -5.144 & $<0.001$ \\
\hline $\mathrm{LDL}-\mathrm{C}(\mathrm{mmol} / \mathrm{L})^{\mathrm{a}}$ & $2.88 \pm 1.265$ & $2.71 \pm 1.005$ & $3.06 \pm 1.473$ & -2.131 & 0.034 \\
\hline $\mathrm{HDL}-\mathrm{C}(\mathrm{mmol} / \mathrm{L})^{\mathrm{a}}$ & $1.09 \pm 0.353$ & $1.06 \pm 0.300$ & $1.12 \pm 0.399$ & -1.379 & 0.169 \\
\hline \multicolumn{6}{|l|}{ Renal function } \\
\hline $\mathrm{Cr}(\mathrm{mmol} / \mathrm{L})^{\mathrm{b}}$ & $120.34 \pm 128.697$ & $101.54 \pm 119.931$ & $139.93 \pm 134.969$ & -5.155 & $<0.001$ \\
\hline $\mathrm{BUN}(\mathrm{mmol} / \mathrm{L})^{\mathrm{b}}$ & $7.66 \pm 8.466$ & $8.19 \pm 10.877$ & $7.12 \pm 4.805$ & -0.207 & 0.836 \\
\hline Positive urine protein ${ }^{c}$ & $155(64.3 \%)$ & $84(67.7 \%)$ & $71(60.7 \%)$ & 1.307 & 0.253 \\
\hline \multicolumn{6}{|l|}{ Blood glucose levels } \\
\hline $\begin{array}{l}\text { Fasting blood glucose (mmol/ } \\
\mathrm{L})^{\mathrm{a}}\end{array}$ & $8.29 \pm 2.913$ & $8.86 \pm 2.463$ & $7.94 \pm 3.121$ & 2.161 & 0.032 \\
\hline $\begin{array}{l}\text { Postprandial blood glucose } \\
(\mathrm{mmol} / \mathrm{L})^{\mathrm{a}}\end{array}$ & $11.64 \pm 3.759$ & $12.76 \pm 3.422$ & $10.94 \pm 3.804$ & 3.345 & 0.001 \\
\hline \multicolumn{6}{|l|}{ Cardiac function parameters } \\
\hline $\operatorname{LVID}(\mathrm{mm})^{\mathrm{a}}$ & $37.48 \pm 6.877$ & $35.85 \pm 5.214$ & $44.63 \pm 8.652$ & 19.271 & $<0.001$ \\
\hline $\operatorname{LVEDD}(\mathrm{mm})^{\mathrm{a}}$ & $47.39 \pm 7.220$ & $45.89 \pm 6.273$ & $53.22 \pm 7.797$ & 6.369 & 0.013 \\
\hline $\operatorname{LVEF}(\%)^{\mathrm{a}}$ & $66.47 \pm 10.851$ & $67.30 \pm 8.171$ & $53.03 \pm 12.834$ & 17.665 & $<0.001$ \\
\hline $\begin{array}{l}\text { Segmental wall motion } \\
\text { abnormalities }(n)^{c}\end{array}$ & $16(11.6 \%)$ & $7(6.7 \%)$ & $9(27.3 \%)$ & 10.401 & 0.001 \\
\hline
\end{tabular}

distal limbs, and neuropathy makes patients insensitive to pain [7]. Moreover, DM prevention is insufficiently publicized, and patients have limited access to relevant knowledge about DM. Macao has limited medical resources but a large number of patients with DM. In contrast to patients in Beijing, short-term follow-up monitoring of DM patients is impossible in Macao. Most patients return to the clinic more than half a year after taking medicine. During this period, their blood glucose levels are not regularly monitored. Medical resources during hospitalization are also more limited in Macao, so the management of DM is usually delayed.
Furthermore, Macao lacks specialists such as vascular surgeons and orthopedic surgeons, and diabetic foot diseases cannot be promptly managed. General practitioners in the community health center lack relevant professional knowledge, so DM and diabetic foot disease are usually underdiagnosed. As a result of these factors, diabetic foot disease occurs in younger populations and progresses more rapidly in Macao than in Beijing.

$\mathrm{DM}$ is an independent risk factor for the occurrence and development of arteriosclerosis. Vascular sclerosis in DM patients is more severe than that in non-DM patients. The leading 
Table 4 Clinical characteristics of diabetic foot disease

\begin{tabular}{|c|c|c|c|c|c|}
\hline Characteristic & $\begin{array}{l}\text { Total } \\
(n=243)\end{array}$ & $\begin{array}{l}\text { Beijing group } \\
(n=124)\end{array}$ & $\begin{array}{l}\text { Macao group } \\
(n=119)\end{array}$ & $\begin{array}{l}\text { Statistical } \\
\text { value }\end{array}$ & $P$ value \\
\hline \multicolumn{6}{|l|}{$\mathrm{DM}$} \\
\hline Onset age (years) ${ }^{a}$ & $55.86 \pm 12.753$ & $55.37 \pm 11.411$ & $56.37 \pm 14.047$ & -0.609 & 0.543 \\
\hline Duration (years) ${ }^{\mathrm{a}}$ & $13.15 \pm 8.064$ & $15.49 \pm 8.159$ & $10.71 \pm 7.224$ & 4.834 & $<0.001$ \\
\hline \multicolumn{6}{|l|}{ Diabetic foot disease } \\
\hline Onset age (years) ${ }^{\mathrm{a}}$ & $65.51 \pm 11.358$ & $67.10 \pm 9.243$ & $63.85 \pm 13.040$ & 2.237 & 0.026 \\
\hline Duration (months) ${ }^{\mathrm{b}}$ & $40.18 \pm 28.622$ & $44.48 \pm 30.726$ & $35.69 \pm 25.617$ & 1.735 & 0.028 \\
\hline Progression time of diabetic foot disease (years) ${ }^{b}$ & $9.65 \pm 7.797$ & $11.73 \pm 8.067$ & $7.48 \pm 6.894$ & 4.412 & $<0.001$ \\
\hline Left ankle $\mathrm{ABI}^{\mathrm{a}}$ & $0.62 \pm 0.273$ & $0.57 \pm 0.249$ & $0.68 \pm 0.286$ & -3.222 & 0.001 \\
\hline Right ankle $\mathrm{ABI}^{\mathrm{a}}$ & $0.67 \pm 0.306$ & $0.63 \pm 0.303$ & $0.72 \pm 0.304$ & -2.363 & 0.019 \\
\hline \multicolumn{6}{|l|}{ Affected lower extremity ${ }^{c}$} \\
\hline Left lower extremity & $103(42.7 \%)$ & $73(59.8 \%)$ & $30(25.2 \%)$ & 54.205 & $<0.001$ \\
\hline Right lower extremity & $58(24.1 \%)$ & $35(28.7 \%)$ & $23(19.3 \%)$ & & \\
\hline Bilateral lower extremities & $80(33.2 \%)$ & $14(11.5 \%)$ & $66(55.5 \%)$ & & \\
\hline \multicolumn{6}{|l|}{$\begin{array}{l}\text { Severity of diabetic foot disease on the } \\
\text { left leg }\end{array}$} \\
\hline Mild (25-49\%) & $43(17.7 \%)$ & $12(9.7 \%)$ & $31(26.1 \%)$ & -4.380 & $<0.001$ \\
\hline Moderate $(50-74 \%)$ & $48(19.8 \%)$ & $14(11.3 \%)$ & $34(28.6 \%)$ & & \\
\hline Severe $(75-99 \%)$ & $110(45.3 \%)$ & $74(59.6 \%)$ & $36(30.3 \%)$ & & \\
\hline Occlusion & $42(17.3 \%)$ & $24(19.4 \%)$ & $18(15.1 \%)$ & & \\
\hline \multicolumn{6}{|l|}{ Severity of diabetic foot disease on the right leg ${ }^{b}$} \\
\hline Mild (25-49\%) & $73(30.0 \%)$ & $38(30.6 \%)$ & $35(29.4 \%)$ & -0.654 & 0.513 \\
\hline Moderate $(50-74 \%)$ & $48(19.8 \%)$ & $16(12.9 \%)$ & $32(26.9 \%)$ & & \\
\hline Severe (75-99\%) & $76(31.3 \%)$ & $48(38.7 \%)$ & $28(23.5 \%)$ & & \\
\hline Occlusion & $46(18.9 \%)$ & $22(17.7 \%)$ & $24(20.2 \%)$ & & \\
\hline \multicolumn{6}{|l|}{ Clinical symptoms ${ }^{\mathrm{b}}$} \\
\hline Asymptomatic & $12(4.9 \%)$ & $5(4.0 \%)$ & $7(5.9 \%)$ & -1.766 & 0.077 \\
\hline Intermittent claudication & $116(47.7 \%)$ & $57(46.0 \%)$ & $59(49.6 \%)$ & & \\
\hline Rest pain & $57(23.5 \%)$ & $23(18.5 \%)$ & $34(28.6 \%)$ & & \\
\hline Ulceration and gangrene & $58(23.9 \%)$ & $39(31.5 \%)$ & $19(16.0 \%)$ & & \\
\hline
\end{tabular}

$A B I$ ankle-brachial index

${ }^{\text {a }}$ Independent-sample $t$ test

b Rank sum test

c Chi-square test 
Table 5 Treatment modalities of diabetic foot disease

\begin{tabular}{lcccrc}
\hline Treatment modality & Total $(\boldsymbol{n}=\mathbf{2 4 3})$ & Beijing group $(\boldsymbol{n}=\mathbf{1 2 4})$ & Macao group $(\boldsymbol{n}=\mathbf{1 1 9})$ & $\boldsymbol{\chi}^{\mathbf{2}}$ value & $\boldsymbol{P}$ value \\
\hline Surgical treatment & $144(59.3 \%)$ & $119(96.0 \%)$ & $25(21.0 \%)$ & 141.328 & $<0.001$ \\
Balloon dilatation & $77(31.7 \%)$ & $53(42.7 \%)$ & $24(20.2 \%)$ & 14.295 & $<0.001$ \\
Stent implantation & $105(43.2 \%)$ & $82(66.1 \%)$ & $23(19.3 \%)$ & 54.203 & $<0.001$ \\
Catheter thrombolysis & $17(7.0 \%)$ & $17(13.7 \%)$ & $0(0.0 \%)$ & 17.542 & $<0.001$ \\
Amputation & $20(8.2 \%)$ & $20(16.1 \%)$ & $0(0.0 \%)$ & 20.915 & $<0.001$ \\
Pharmacotherapy & $221(90.9 \%)$ & $103(83.1 \%)$ & $118(99.2 \%)$ & 19.105 & $<0.001$ \\
Biguanides & $66(27.2 \%)$ & $15(12.1 \%)$ & $51(42.9 \%)$ & 29.043 & $<0.001$ \\
Sulfonylureas & $47(19.3 \%)$ & $8(6.5 \%)$ & $39(32.8 \%)$ & 26.968 & $<0.001$ \\
Insulin & $124(51.0 \%)$ & $50(40.3 \%)$ & $74(62.2 \%)$ & 11.614 & 0.001 \\
Acarbose & $33(13.6 \%)$ & $28(22.6 \%)$ & $5(4.2 \%)$ & 17.478 & $<0.001$ \\
\hline
\end{tabular}

Table 6 Cause of death in patients with diabetic foot disease

\begin{tabular}{llllll}
\hline Cause of death & Total $(\boldsymbol{n}=\mathbf{3 6})$ & Beijing group $(\boldsymbol{n}=\mathbf{1 4})$ & Macao group $(\boldsymbol{n}=\mathbf{2 2})$ & $\chi^{2}$ value & $\boldsymbol{P}$ value \\
\hline Cardiac failure & $26(72.2 \%)$ & $10(71.4 \%)$ & $16(72.7 \%)$ & 2.578 & 0.883 \\
Respiratory failure & $6(16.7 \%)$ & $2(14.3 \%)$ & $4(18.2 \%)$ & & \\
Uremia & $1(2.8 \%)$ & $1(7.1 \%)$ & $0(0.0 \%)$ & \\
Septicemia & $2(5.6 \%)$ & $1(7.1 \%)$ & $1(4.5 \%)$ & \\
Cerebral hemorrhage & $1(2.8 \%)$ & $0(0.0 \%)$ & $1(4.5 \%)$ & \\
\hline
\end{tabular}

cause of death was cardiac failure in both groups, suggesting that cardiac dysfunction is common in patients with diabetic foot disease. The surgical treatment rate was higher in the Beijing group; existing evidence has shown that early surgery or interventional therapy can promote wound healing [7]. Surgical treatment can obviously improve the blood supply to the lower extremities, increasing blood perfusion of the foot and improving the local oxygen supply. More patients received pharmacotherapy in Macao, which may be related to the referral appointment system used there. The clinicians' lack of knowledge and an absence of multidisciplinary cooperation also contribute to the high rate of drug treatment in Macao. Wound healing is multifactorial, and wound nursing should be emphasized.

Smoking is a risk factor for the occurrence and development of diabetic foot disease. Smoking can significantly reduce the onset age and aggravate the severity of diabetic foot disease, and short-term smoking (length of smoking history $<30$ years) can also shorten the progression time of diabetic foot disease. Our study also showed that household income was negatively correlated with onset age. We speculate that these results may be attributed to differences in lifestyle between the two cities. Therefore, the prevention of DM and diabetic foot disease needs to be encouraged in the Macao population. Healthy lifestyles and family 
Table 7 Univariate analysis of factors associated with the onset age of diabetic foot disease

\begin{tabular}{llllll}
\hline Variate & $\begin{array}{l}\text { Regression } \\
\text { coefficient }(\boldsymbol{b})\end{array}$ & $\begin{array}{l}\text { Standardized regression } \\
\text { coefficient }(\boldsymbol{\beta})\end{array}$ & $\boldsymbol{t}$ value & $\boldsymbol{P}$ value & 95\% CI \\
\hline District (Beijing, Macao) & -3.256 & -0.144 & -2.253 & 0.025 & $-6.103,-0.409$ \\
Gender & -3.023 & -0.130 & -2.030 & 0.043 & $-5.957,-0.089$ \\
Income & -3.875 & -0.250 & -3.912 & $<0.001$ & $-5.826,-1.923$ \\
Marital status & -3.697 & -0.148 & -2.328 & 0.021 & $-6.824,-0.569$ \\
Insulin usage & -3.117 & -0.137 & -2.155 & 0.032 & $-5.967,-0.267$ \\
Smoking history & -4.353 & -0.190 & -3.009 & 0.003 & $-7.203,-1.503$ \\
\hline
\end{tabular}

Only statistically significant variates are presented

Table 8 Multivariate linear regression analysis of factors associated with the onset age of diabetic foot disease

\begin{tabular}{lllrrr}
\hline Variate & $\begin{array}{l}\text { Regression } \\
\text { coefficient }(\boldsymbol{b})\end{array}$ & $\begin{array}{l}\text { Standardized regression } \\
\text { coefficient }(\boldsymbol{\beta})\end{array}$ & $\boldsymbol{t}$ value & $\boldsymbol{P}$ value & $\mathbf{9 5 \%} \mathbf{C I}$ \\
\hline Income & -3.916 & -0.253 & -4.044 & $<0.001$ & $-5.824,-2.008$ \\
Smoking history & -4.895 & -0.212 & -3.395 & 0.001 & $-7.737,-2.054$ \\
\hline
\end{tabular}

Only statistically significant variates are presented

Table 9 Univariate analysis of factors associated with the progression time of diabetic foot disease

\begin{tabular}{|c|c|c|c|c|c|c|}
\hline Variate & $B$ value & Standard error & Wald & $P$ value & $95 \% \mathrm{CI}$ & $\operatorname{Exp}(B) 95 \% C I$ \\
\hline \multicolumn{7}{|c|}{ Length of smoking history } \\
\hline 0 years & -0.580 & 0.145 & 15.882 & $<0.001$ & $-0.865,-0.295$ & $0.560(0.421,0.745)$ \\
\hline $1-30$ years & -1.762 & 0.196 & 80.822 & $<0.001$ & $-2.146,-1.378$ & $0.172(0.117,0.252)$ \\
\hline$>31$ years & 0 & - & - & - & - & - \\
\hline \multicolumn{7}{|l|}{ District } \\
\hline Beijing & 1.146 & 0.251 & 20.859 & $<0.001$ & $0.654,1.637$ & $3.144(1.363,7.255)$ \\
\hline Macao & 0 & - & - & - & - & - \\
\hline \multicolumn{7}{|l|}{ Education level } \\
\hline$\leq$ Elementary school & -1.220 & 0.176 & 48.226 & $<0.001$ & $-1.565,-0.876$ & $0.295(0.209,0.416)$ \\
\hline$<$ Junior college & -1.362 & 0.174 & 61.039 & $<0.001$ & $-1.703,-1.020$ & $0.256(0.182,0.361)$ \\
\hline$\geq$ Junior college & 0 & - & - & - & - & - \\
\hline $\mathrm{TG}(\mathrm{mmol} / \mathrm{L})$ & -0.226 & 0.088 & 6.563 & 0.010 & $-0.398,-0.053$ & $0.798(0.671,0.948)$ \\
\hline $\mathrm{TC}(\mathrm{mmol} / \mathrm{L})$ & -0.203 & 0.071 & 8.203 & 0.004 & $-0.343,-0.064$ & $0.816(0.710,0.938)$ \\
\hline $\mathrm{RBC}\left(\times 10^{12} / \mathrm{L}\right)$ & -0.342 & 0.088 & 15.021 & $<0.001$ & $-0.515,-0.169$ & $0.710(0.598,0.844)$ \\
\hline $\operatorname{PLT}\left(\times 10^{9} / \mathrm{L}\right)$ & -0.004 & 0.014 & 6.462 & 0.011 & $0.001,0.006$ & $1.004(1.001,1.006)$ \\
\hline Income ( 10,000 yuan $)$ & -0.639 & 0.242 & 7.002 & 0.008 & $-1.113,-0.166$ & $0.528(0.329,0.847)$ \\
\hline
\end{tabular}

Only statistically significant variates are presented 
Table 10 Multivariate linear regression analysis of factors associated with the progression time of diabetic foot disease

\begin{tabular}{lllllll}
\hline Variate & $\boldsymbol{B}$ value & Standard error & Wald & $\boldsymbol{P}$ value & $\mathbf{9 5 \%} \mathbf{C I}$ & $\operatorname{Exp}(\boldsymbol{B}) \mathbf{9 5 \%} \boldsymbol{C I}$ \\
\hline (0-3 years): ( $\geq$ 4 years) & -6.687 & 1.003 & 44.420 & $<0.001$ & $-8.654,-4.721$ & $0.001(0.000,0.009)$ \\
$(0-10$ years): ( $\geq 11$ years) & -4.092 & 0.925 & 19.555 & $<0.001$ & $-5.905,-2.278$ & $0.017(0.003,0.102)$ \\
Onset age (years) & -0.080 & 0.013 & 37.140 & $<0.001$ & $-0.106,-0.054$ & $0.923(0.899,0.947)$ \\
Length of smoking history & & & & & & \\
0 years & 0.008 & 0.359 & 0.001 & 0.982 & $-0.695,0.712$ & $1.008(0.499,2.037)$ \\
$1-30$ years & -1.445 & 0.487 & 8.789 & 0.003 & $-2.400,-0.490$ & $0.236(0.091,0.613)$ \\
$\geq 31$ years & 0 & - & - & - & - & - \\
\hline
\end{tabular}

Only statistically significant variates are presented

Table 11 Severity of diabetic foot disease

\begin{tabular}{lccccc}
\hline Severity & \multicolumn{2}{l}{ Right leg } & & Total \\
\cline { 2 - 5 } & Mild & Moderate & Severe & Occlusion & \\
\hline Left leg & 8 & 14 & 12 & 9 & 43 \\
Mild & 19 & 17 & 10 & 2 & 48 \\
Moderate & 37 & 13 & 44 & 16 & 110 \\
Severe & 9 & 4 & 10 & 19 & 42 \\
Occlusion & 73 & 48 & 76 & 46 & 243 \\
Total & & &
\end{tabular}

care are crucial to reducing the incidence of diabetic foot disease. Age was positively correlated with the progression and severity of diabetic foot disease. With the increase of age, the risk factors of arteriosclerosis and DM increase the probability of infection.

Renal dysfunction and blood coagulation dysfunction can adversely affect the survival time of patients with diabetic foot disease. Renal dysfunction is a severe and common complication of DM. The incidence of renal dysfunction is much higher in Macao, and many patients require early dialysis. Frequent dialysis significantly reduces patient quality of life. Arteriosclerosis is more serious in DM patients who undergo dialysis. Both DM and uremia can lead to neuropathy, resulting in a refractory wound that does not heal for a long time. Local wound infection can be associated with pain, swelling, and exudation, affecting the utilization of the lower extremities and further reducing quality of life. Most patients have multiple complications, especially arteriosclerosis-related ischemic diseases such as coronary heart disease and cerebral arteriosclerosis, significantly increasing the risk of cardiac failure. In the current study, cardiac failure was the leading cause of death in both groups. Additionally, chronic consumption reduced the immunity of patients and increased the risk of systemic infection. Lung infection also accounted for a large proportion of the deaths in the two groups. Therefore, the benefits of improving renal function and blood coagulation function should be highlighted in the treatment of diabetic foot disease. 
Table 12 Univariate analysis of factors associated with the severity of diabetic foot disease

\begin{tabular}{|c|c|c|c|c|c|c|}
\hline Variate & $B$ value & $\begin{array}{l}\text { Standard } \\
\text { error }\end{array}$ & $95 \% \mathrm{CI}$ & Wald & $P$ value & $\operatorname{Exp}(B) 95 \% \mathrm{CI}$ \\
\hline Age & 0.030 & 0.009 & $0.012,0.048$ & 10.574 & 0.001 & $\begin{array}{l}1.030(1.012, \\
1.049)\end{array}$ \\
\hline \multicolumn{7}{|l|}{ District } \\
\hline Beijing & 0.961 & 0.200 & $0.568,1.354$ & 22.998 & $<0.001$ & $\begin{array}{l}2.615(1.765 \\
3.874)\end{array}$ \\
\hline Macao & 0 & - & - & - & - & - \\
\hline \multicolumn{7}{|l|}{ Length of smoking history } \\
\hline 0 years & -1.325 & 0.260 & $\begin{array}{l}-1.835 \\
-0.815\end{array}$ & 25.923 & $<0.001$ & $\begin{array}{l}0.266(0.160 \\
0.443)\end{array}$ \\
\hline $1-30$ years & -1.597 & 0.362 & $\begin{array}{l}-2.307 \\
-0.887\end{array}$ & 19.417 & $<0.001$ & $\begin{array}{l}0.203(0.100 \\
0.412)\end{array}$ \\
\hline$\geq 31$ years & 0 & - & - & - & - & - \\
\hline Systolic pressure & 0.012 & 0.005 & $0.002,0.022$ & 5.162 & 0.023 & $\begin{array}{l}1.012(1.002 \\
1.022)\end{array}$ \\
\hline \multicolumn{7}{|l|}{ Marital status } \\
\hline Single/divorced/widowed & 0.844 & 0.223 & $0.407,1.281$ & 14.348 & $<0.001$ & $\begin{array}{l}2.326(1.503 \\
3.601)\end{array}$ \\
\hline Married/cohabiting & 0 & - & - & - & - & - \\
\hline $\operatorname{ALT}(\mathrm{U} / \mathrm{L})$ & -0.014 & 0.005 & $\begin{array}{r}-0.025 \\
-0.004\end{array}$ & 6.903 & 0.009 & $\begin{array}{l}0.986(0.976 \\
0.996)\end{array}$ \\
\hline $\mathrm{RBC}\left(\times 10^{12} / \mathrm{L}\right)$ & -0.313 & 0.082 & $\begin{aligned}- & 0.474 \\
- & 0.153\end{aligned}$ & 14.603 & $<0.001$ & $\begin{array}{l}0.731(0.623 \\
0.859)\end{array}$ \\
\hline $\operatorname{PLT}\left(\times 10^{9} / \mathrm{L}\right)$ & 0.005 & 0.001 & $0.003,0.008$ & 15.194 & $<0.001$ & $\begin{array}{l}1.005(1.003 \\
1.008)\end{array}$ \\
\hline Income ( 10,000 yuan $)$ & -0.440 & 0.212 & $\begin{array}{l}-0.855 \\
-0.026\end{array}$ & 4.333 & 0.037 & $\begin{array}{l}0.644(0.425 \\
0.975)\end{array}$ \\
\hline $\begin{array}{l}\text { Clinical course of diabetic foot disease } \\
\text { (years) }\end{array}$ & 0.011 & 0.004 & $\begin{array}{r}-0.004 \\
-0.018\end{array}$ & 8.628 & 0.003 & $\begin{array}{l}1.011(1.004 \\
1.018)\end{array}$ \\
\hline
\end{tabular}

Only statistically significant variates are presented

Currently, the prevention and treatment of diabetic foot disease is an important health care issue around the world [8, 9]. Better health care services and management are greatly beneficial for patients with DM. Therefore, it is recommended that health education should be strengthened and popularized, the hierarchical management of DM and diabetic foot disease should be instituted $[3,8,10]$, and a standardized evaluation system should be established, including early diagnosis of diabetic foot disease (skin condition, toenail condition, foot 
Table 13 Multivariate linear regression analysis of factors associated with the severity of diabetic foot disease

\begin{tabular}{|c|c|c|c|c|c|c|}
\hline Variate & $B$ value & $\begin{array}{l}\text { Standard } \\
\text { error }\end{array}$ & 95\% CI & Wald & $P$ value & $\operatorname{Exp}(B) 95 \% \mathrm{CI}$ \\
\hline Age & 0.031 & 0.011 & $0.010,0.052$ & 8.175 & 0.004 & $\begin{array}{l}1.032(1.010 \\
1.054)\end{array}$ \\
\hline $\begin{array}{l}\text { Clinical course of diabetic foot disease } \\
\text { (years) }\end{array}$ & 0.009 & 0.004 & $0.001,0.017$ & 5.226 & 0.022 & $\begin{array}{l}1.009(1.001 \\
1.017)\end{array}$ \\
\hline \multicolumn{7}{|l|}{ Length of smoking history } \\
\hline 0 years & -1.468 & 0.291 & $\begin{array}{r}-2.038 \\
-0.898\end{array}$ & 25.451 & $<0.001$ & $\begin{array}{l}0.230(0.130 \\
0.408)\end{array}$ \\
\hline $1-30$ years & -1.144 & 0.378 & $\begin{array}{r}-1.884 \\
-0.403\end{array}$ & 9.168 & 0.002 & $\begin{array}{c}0.319(0.152 \\
0.668)\end{array}$ \\
\hline$\geq 31$ years & 0 & - & - & - & - & - \\
\hline
\end{tabular}

Only statistically significant variates are presented

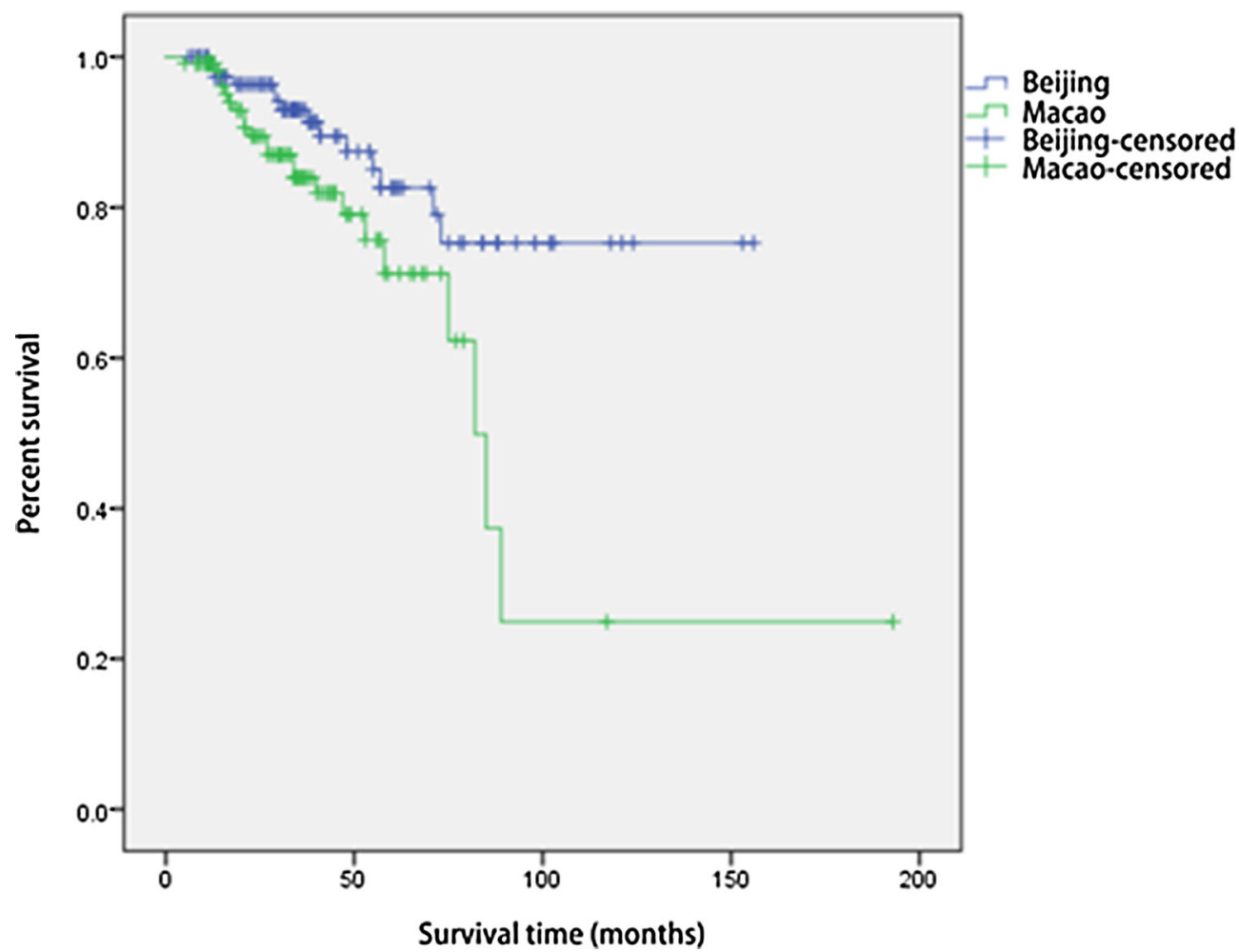

Fig. 1 Kaplan-Meier analysis showed that the average survival time in the Beijing group (129.306 months; $95 \%$ confidence interval: 116.101-142.511 months) was significantly longer than that in the Macao group (96.700 months; $95 \%$ confidence interval: 64.684-128.717 months) 
Table 14 Univariate analysis of factors associated with the survival time of patients with diabetic foot disease

\begin{tabular}{lllllll}
\hline Variate & $\boldsymbol{B}$ value & Standard error & Wald & $\boldsymbol{P}$ value & HR & 95\% CI \\
\hline District & & & & & & \\
Beijing & 0 & - & - & - & - & - \\
Macao & 0.922 & 0.355 & 6.727 & 0.009 & 2.514 & $1.253,5.046$ \\
Occupation & & & & & & \\
Primary industry & & & 4.483 & 0.214 & & \\
Secondary industry & -1.949 & 1.323 & 2.502 & 0.114 & 0.142 & $0.013,1.593$ \\
Tertiary industry & -1.677 & 0.832 & 4.060 & 0.044 & 0.187 & $0.037,0.955$ \\
Others & -1.344 & 0.752 & 3.191 & 0.074 & 0.261 & $0.060,1.140$ \\
Hyperlipidemia & 0.795 & 0.347 & 5.260 & 0.022 & 2.214 & $1.123,4.367$ \\
Renal dysfunction & 1.553 & 0.346 & 20.191 & $<0.001$ & 4.724 & $2.400,9.299$ \\
Cr (mmol/L) & 0.003 & 0.001 & 28.713 & $<0.001$ & 1.003 & $1.002,1.004$ \\
BUN (mmol/L) & 0.051 & 0.011 & 19.949 & $<0.001$ & 1.053 & $1.029,1.077$ \\
Stent implantation & -0.957 & 0.387 & 6.110 & 0.013 & 0.384 & $0.180,0.820$ \\
AST (U/L) & 0.009 & 0.004 & 4.869 & 0.027 & 1.009 & $1.001,1.017$ \\
HGB (g/L) & -0.035 & 0.009 & 14.041 & 0.001 & 0.966 & $0.949,0.984$ \\
PLT (× 10 $/ \mathrm{L})$ & -0.006 & 0.002 & 7.044 & 0.008 & 0.994 & $0.990,0.998$ \\
APTT (s) & 0.046 & 0.013 & 13.337 & $<0.001$ & 1.047 & $1.022,1.073$ \\
Positive urine protein & 1.078 & 0.362 & 8.858 & 0.003 & 2.940 & $1.445,5.980$ \\
\hline Ony stistal & & & & &
\end{tabular}

Only statistically significant variates are presented

Table 15 Multivariate linear regression analysis of factors associated with the survival time of patients with diabetic foot disease

\begin{tabular}{lllllll}
\hline Variate & $\boldsymbol{B}$ value & Standard error & Wald & $\boldsymbol{P}$ value & HR & 95\% CI \\
\hline Renal dysfunction & 1.720 & 0.372 & 21.421 & 0.003 & 5.584 & $2.696,11.569$ \\
APTT & 0.058 & 0.015 & 15.473 & 0.001 & 1.060 & $1.029,1.090$ \\
\hline
\end{tabular}

Only statistically significant variates are presented

deformity, etc.), evaluation of lower-limb blood vessels (artery ultrasound or CTA), and neurological assessments (sensory disturbance or motor abnormalities) [5, 11]. Furthermore, multidisciplinary cooperation in the treatment of diabetic foot disease and the establishment of a follow-up system that can provide a long-term individualized management strategy are important [12-14].
There are some limitations of this study. Firstly, all subjects were enrolled from local hospitals, so selection bias was unavoidable. Secondly, this was a retrospective case-control study, so there may be recall bias. Thirdly, the sample size was limited. In the future, a prospective multicenter study is warranted. 


\section{CONCLUSIONS}

We found that smoking was a risk factor for the occurrence and development of diabetic foot; it significantly reduced the onset age and aggravated the severity of this disease. The onset age of diabetic foot was lower in high-income patients, and prevention should be encouraged in this population. Elderly age may be associated with a rapidly developing and severe diabetic foot. The clinical course was also associated with the severity of diabetic foot. Renal and coagulation function should be closely monitored during the treatment of diabetic foot.

\section{ACKNOWLEDGEMENTS}

We thank the participants of the study.

Funding. This work was supported by the Science and Technology Development Fund of the Macao Special Administrative Region (110/ 2015/A). The study sponsor is also funding the journal's Rapid Service Fee. All authors had full access to all of the data in this study and take complete responsibility for the integrity of the data and accuracy of the data analysis.

Authorship. All named authors meet the International Committee of Medical Journal Editors (ICMJE) criteria for authorship for this article, take responsibility for the integrity of the work as a whole, and have given their approval for this version to be published.

Authorship Contributions. All authors were involved in drafting and revising this article. $\mathrm{YZ}, \mathrm{NC}$, and GL planned the analysis; TL conducted the analysis; CI, SC, and CW contributed to data verification and the creation of tables and figures; QW was the lead statistician responsible for data handling in each study; HL reviewed the manuscript and performed substantial editing. All authors contributed to the review and interpretation of the results, revised the manuscript for intellectual content, and approved the final version of the manuscript.
Disclosures. Yang Zhang, Nim Choi, Gangzhu Liang, Tan Li, Chunman Ieong, Sio-yin Chu, Cheng-jie Wang, Qi Wang, and Hui Li have nothing to disclose.

Compliance with Ethics Guidelines. The trial was conducted in accordance with the Declaration of Helsinki, the International Conference on Harmonisation guidelines for good clinical practice, and all applicable laws and regulations. This study was approved by the Ethics Committee of Beijing Chaoyang Hospital. Written informed consent was obtained from each participant.

Data Availability. The datasets obtained and/or analyzed during the current study are available from the corresponding author on reasonable request.

Open Access. This article is licensed under a Creative Commons Attribution-NonCommercial 4.0 International License, which permits any non-commercial use, sharing, adaptation, distribution and reproduction in any medium or format, as long as you give appropriate credit to the original author(s) and the source, provide a link to the Creative Commons licence, and indicate if changes were made. The images or other third party material in this article are included in the article's Creative Commons licence, unless indicated otherwise in a credit line to the material. If material is not included in the article's Creative Commons licence and your intended use is not permitted by statutory regulation or exceeds the permitted use, you will need to obtain permission directly from the copyright holder. To view a copy of this licence, visit http:// creativecommons.org/licenses/by-nc/4.0/.

\section{REFERENCES}

1. Hicks CW, Selvin E. Epidemiology of peripheral neuropathy and lower extremity disease in diabetes. Curr Diab Rep. 2019;19(10):86. 
2. Cho NH, Whiting D, Guariguata L, et al. IDF diabetes atlas. Brussels: International Diabetes Federation; 2013.

3. Lim JZM, Ng NSL, Thomas C. Prevention and treatment of diabetic foot ulcers. J R Soc Med. 2017;110(3):104-9.

4. Kalish J, Hamdan A. Management of diabetic foot problems. J Vasc Surg. 2010;51(2):476-86.

5. Naidoo P, Liu VJ, Mautone M, Bergin S. Lower limb complications of diabetes mellitus: a comprehensive review with clinicopathological insights from a dedicated high-risk diabetic foot multidisciplinary team. Br J Radiol. 2015;88(1053):20150135.

6. International Working Group on the Diabetic Foot. International consensus on the diabetic foot and practical guidelines on the management and prevention of the diabetic foot: Amsterdam: International Working Group on the Diabetic Foot; 2007. https://www.idf.org/bookshop.

7. Brownrigg JRW, Apelqvist J, Bakker K, Schaper NC, Hinchliffe RJ. Evidence-based management of PAD $\&$ the diabetic foot. Eur J Vasc Endovasc Surg. 2013;45(6):673-81.

8. Hingorani A, LaMuraglia GM, Henke P, et al. The management of diabetic foot: a clinical practice guideline by the Society for Vascular Surgery in collaboration with the American Podiatric Medical
Association and the Society for Vascular Medicine. J Vasc Surg. 2016;63(2):3S-21S.

9. Bakker K, Apelqvist J, Lipsky BA, Van Netten JJ, Schaper NC, International Working Group on the Diabetic Foot. The 2015 IWGDF guidance documents on prevention and management of foot problems in diabetes: development of an evidencebased global consensus. Diabetes Metab Res Rev. 2016;32:2-6.

10. Uckay I, Aragon-Sanchez J, Lew D, Lipsky BA. Diabetic foot infections: what have we learned in the last 30 years? Int J Infect Dis. 2015;40:81-91.

11. Mishra SC, Chhatbar KC, Kashikar A, Mehndiratta A. Clinical updates: diabetic foot. BMJ. 2017;359: j5064.

12. Armstrong DG, Bharara $M$, White $M$, et al. The impact and outcomes of establishing an integrated interdisciplinary surgical team to care for the diabetic foot. Diabetes Metab Res Rev. 2012;28(6): 514-8.

13. Kintiraki E, Goulis DG. Gestational diabetes mellitus: multi-disciplinary treatment approaches. Metabolism. 2018;86:91-101.

14. Buggy A, Moore Z. The impact of the multidisciplinary team in the management of individuals with diabetic foot ulcers: a systematic review. J Wound Care. 2017;26(6):324-39. 